\title{
A methodology based on GIS for 3D Slope Stability Analysis
}

\author{
Ahmed BOUAJAJ ${ }^{\# 1}$, Lahcen BAHI ${ }^{\# 2}$, Latifa OUADIF ${ }^{\# 3}$ and Khadija BABA ${ }^{\# 4}$

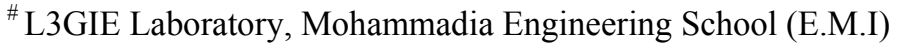 \\ Mohammed V- University in Rabat, Morocco. \\ ${ }^{1}$ ahmed.bouajaj@gmail.com \\ ${ }^{2}$ bahi@emi.ac.ma \\ 3 ouadif@emi.ac.ma \\ ${ }^{4}$ baba.khadija@gmail.com
}

\begin{abstract}
In this paper, we present an analysis of slope stability using Geographic Information Systems (GIS). The methodology is based on the calculation of the safety factor in $2 \mathrm{D}$ and $3 \mathrm{D}$ using GIS. Hovland's Method in 3D and 2D have been used in the stability analysis of the slope located at the 34 kilometer point (KP.34) on the highway in the North of Morocco connecting Tangier to Ksar Sghir. Isohypse and the digital elevation model (DEM) of the studied site have been built from topographical surveys. Results shows that the safety factors (FS) obtained in 3D analysis are about $11 \%$ higher than those obtained in 2D analysis and the slope becomes unstable when the water table level is below $1 \mathrm{~m}$.
\end{abstract}

Keyword-Slope stability, GIS, Hovland Method

\section{INTRODUCTION}

Slope stability problems are frequently encountered in the construction of roads, canals, dikes and dams. Moreover, some natural slopes are or may become unstable. Slope failure can be catastrophic and cause loss of life and considerable damage.The study of a slope includes, besides the recognition of the site and the choice of the mechanical characteristics of the soil, a stability calculation to determine firstly failure curve along which the slip risk is highest, secondly the corresponding value of the safety factor.

Slope stability analysis is applied by two-dimensional 2D and three-dimensional 3D analyses. In slope stability analysis, it is clear that a three-dimensional situation may become important in cases where the geometry of the slope and slip surface varies significantly in the lateral direction, the material properties are highly anisotropic, or the slope is locally loaded [1].

There are several methods of slope stability analysis in 2D and 3D: Limit equilibrium methods (LEM) and Finite Element Methods (FEM). Limit equilibrium methods have been the primary method used in estimating the stability of slope for decades ([2]-[3]).The basic principle of all these methods is to cut the volume of soil studied in a number of slices and apply different forces. The procedures are based on finding a Factor of Safety (FS) for the slope. It is useful to know exactly what percentage the $3 \mathrm{D}$ safety factor is higher than the $2 \mathrm{D}$ analysis.

Since the middle of 70s, many 3D methods of slope stability analysis have been proposed; these methods are traditionally based on an extension of 2D Limit equilibrium methods analysis. The slicing method in 2D analysis has been extended into 3D analysis with columns by various authors due to the popularity of 2D LEM slicing methods. Hovland [4] analyzed a three dimensional slope stability using the method of columns. A new 3D slices method has been proposed by Ugai [5], to analyze 3D slope stability by extending the Fellenius method. Hungr [6] and Huang and Tsai [7] have proposed a three dimensional slope stability analysis method based on an extension of Bishop's simplified 2D method of slices. The 2D general limit equilibrium formulation (Fredlund and krahn [8] ) has been extended by Lam and Fredlund [9] to analyze a 3D slope stability problem using the column method .

A geographical information system (GIS) is a relatively new software tool for geotechnical engineers ([10]). At the same time, using GIS can easily and effectively analyze the problem of 3D slope stability. If a GIS based geotechnical analysis model can be used, all related data are transformed into GIS Raster data and can be stored, retrieved, and analysed to calculate a safety factor. Some researchers have incorporated GIS in the slope stability analysis ([11]-[12]-[13] and [14]).

This paper presents a methodology based on the calculation of the safety factor in $2 \mathrm{D}$ and $3 \mathrm{D}$ using GIS.

\section{Data AND Methodology}

\section{A. Data}

The studied slope is located at the 34 kilometer point (KP.34) on the highway in the North of Morocco connecting Tangier to Ksar Sghir ( Fig. 1). 


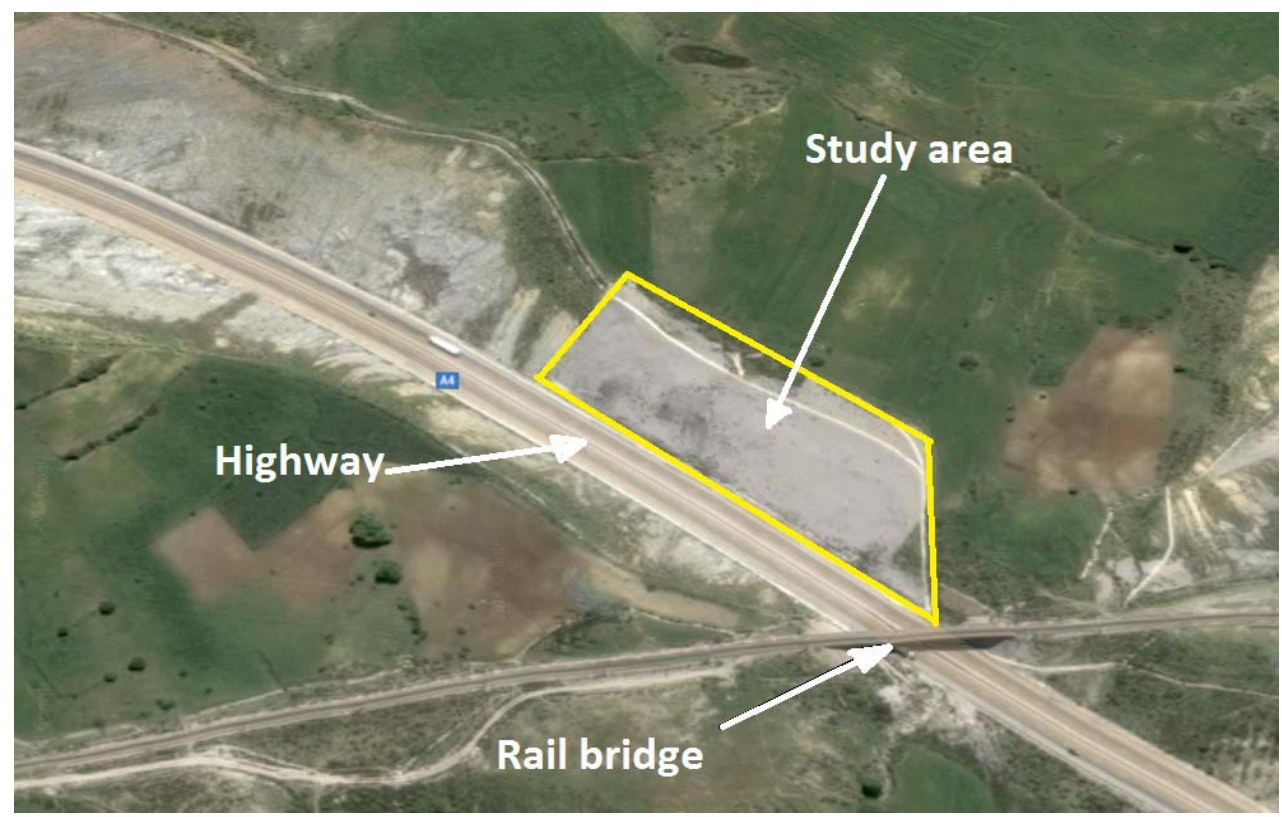

Fig. 1. Location of the study area

Digital elevation model (DEM) has been built from topographical survey, and then the slope and aspect have been determined for each pixel of the studied slope (Fig. 2).

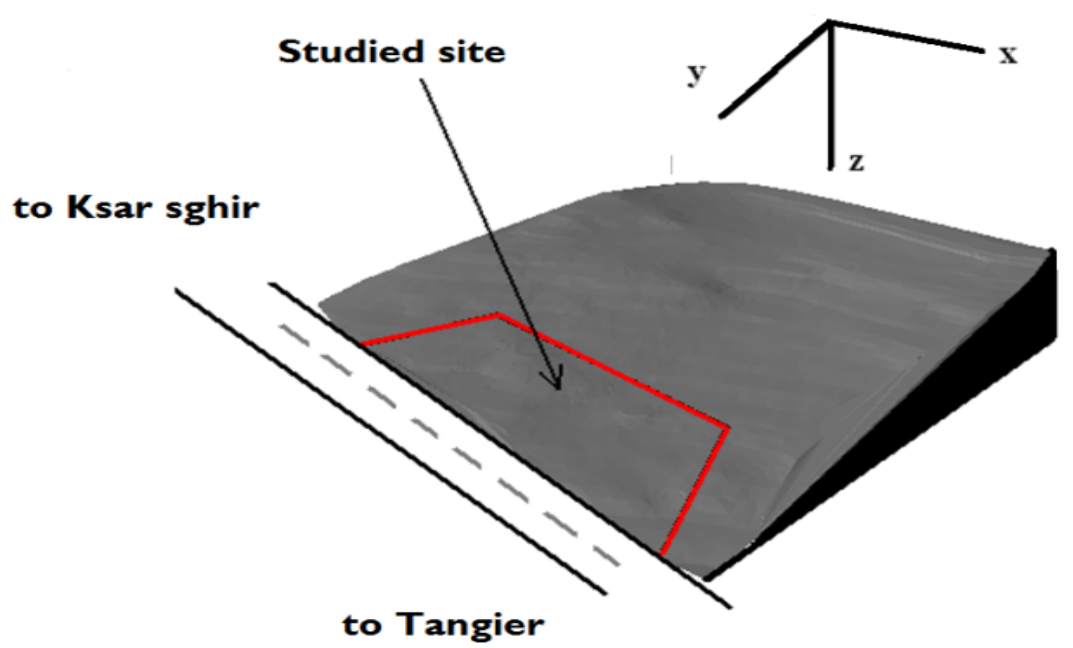

Fig. 2. Studied Slope

\section{B. Methodology}

There are various methods of 2D stability analysis available in practice. Hovland proposed an approach for the 3D slope stability analysis. Hovland's method is an extension of the assumptions used in the twodimensional ordinary method of slices, but columns were used instead of slices. Hovland's method neglects all the inter-column forces acting on the sides of the columns. The shear and normal forces acting on the base of each column are derived as components of the weight of the column.

For Hovland's three-dimensional method, the safety factor is acquired by dividing the soil mass above the failure surface into a number of equal sized vertical soil columns assuming the $\mathrm{x}$ and $\mathrm{y}$-coordinates are perpendicular and in the horizontal plane. The $\mathrm{z}$ coordinate is vertical and the $\mathrm{y}$-coordinate is to be set to the direction of the down slope movement of the failure block. The area of the soil column within the xy plan is defined by $\Delta \mathrm{X}$ and $\Delta \mathrm{Y}$. By assuming both the $\Delta \mathrm{X}$ and $\Delta \mathrm{Y}$ values are constant for all columns. 


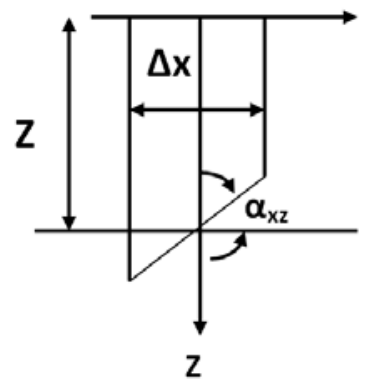

Section

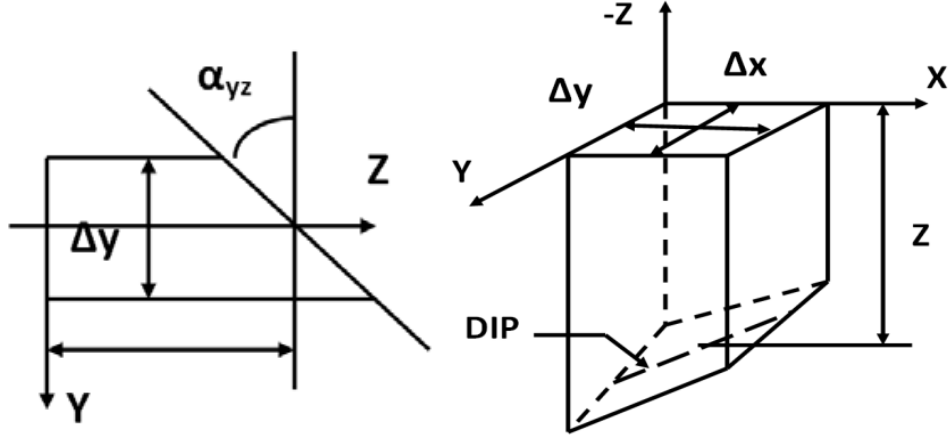

section

shear surface

Fig. 3.Section, and Three-Dimensional Views of one Soil Column [4]

Hovland defines the three-dimensional safety factor as the ratio of total available resistance along the failure surface over the total mobilized stress along it, the three dimensional safety factor for Hovland's method is as follows:

$$
F S_{3 D}=\frac{\sum_{x} \sum_{y}\left[C^{\prime} A+(W J-U) \tan \varphi^{\prime}\right]}{\sum_{x} \sum_{y} W \sin \alpha_{y z}}
$$

$\alpha_{y z}$ and $\alpha_{x z}$ :Inclinations of the base of the column with respect to the $\mathrm{x}_{-}$and $\mathrm{y}_{-}$axes(Fig. 3).

Where:

$$
J=\operatorname{Cos}(D I P)=\frac{1}{\sqrt{1+\tan ^{2} \alpha_{x z}+\tan ^{2} \alpha_{y z}}}
$$

$W=\gamma z \Delta x \Delta y:$ Weight of the column

$$
\begin{aligned}
& A=\Delta x \Delta y\left(\frac{\sqrt{1-\sin ^{2} \alpha_{x z} \sin ^{2} \alpha_{y z}}}{\cos \alpha_{x z} \cos \alpha_{y z}}\right): \text { Area of soil column, with } \sin \theta=\sqrt{1-\sin ^{2} \alpha_{x z} \sin ^{2} \alpha_{y z}} \\
& U=\gamma_{w} h_{w} \frac{\sin \theta}{\cos \alpha_{x z} \cos \alpha_{y z}}: \text { Pore water pressure }
\end{aligned}
$$

Hovland's formula $(*)$ can be explained below by:

$$
F S_{3 D}=\frac{\sum_{x} \sum_{y}\left[\frac{c^{\prime} \Delta x \Delta y \sin \theta}{\cos \alpha_{x z} \cos \alpha_{y z}}+\left(\gamma z \Delta x \Delta y \cos (D I P)-\gamma_{w} h_{w} \frac{\Delta x \Delta y \sin \theta}{\cos \alpha_{x z} \cos \alpha_{y z}}\right) \tan \varphi^{\prime}\right]}{\sum_{x} \sum_{y} \gamma z \Delta x \Delta y \sin \alpha_{y z}}
$$

For $\alpha_{x z}=0$, the safety factor in $2 \mathrm{D}$ can be expressed by:

$$
F S_{2 D}=\frac{\sum_{y}\left[\frac{c^{\prime} \Delta y \sin \theta}{\cos \alpha_{y z}}+\left(\gamma z \Delta y \cos (D I P)-\gamma_{w} h_{w} \frac{\Delta y \sin \theta}{\cos \alpha_{y z}}\right) \tan \varphi^{\prime}\right]}{\sum_{y} \gamma z \Delta y \sin \alpha_{y z}}
$$

Where : $\theta=\frac{\pi}{2}$

Raster Calculator tool of ArcGIS 9.3 that is a part of the Spatial Analyst function was used to calculate the 3D and 2D safety factor for each pixel using Hovland method. Fig. 4 shows the procedures of the safety factor calculation (in 2D and 3D) using ArcGIS9.3. 


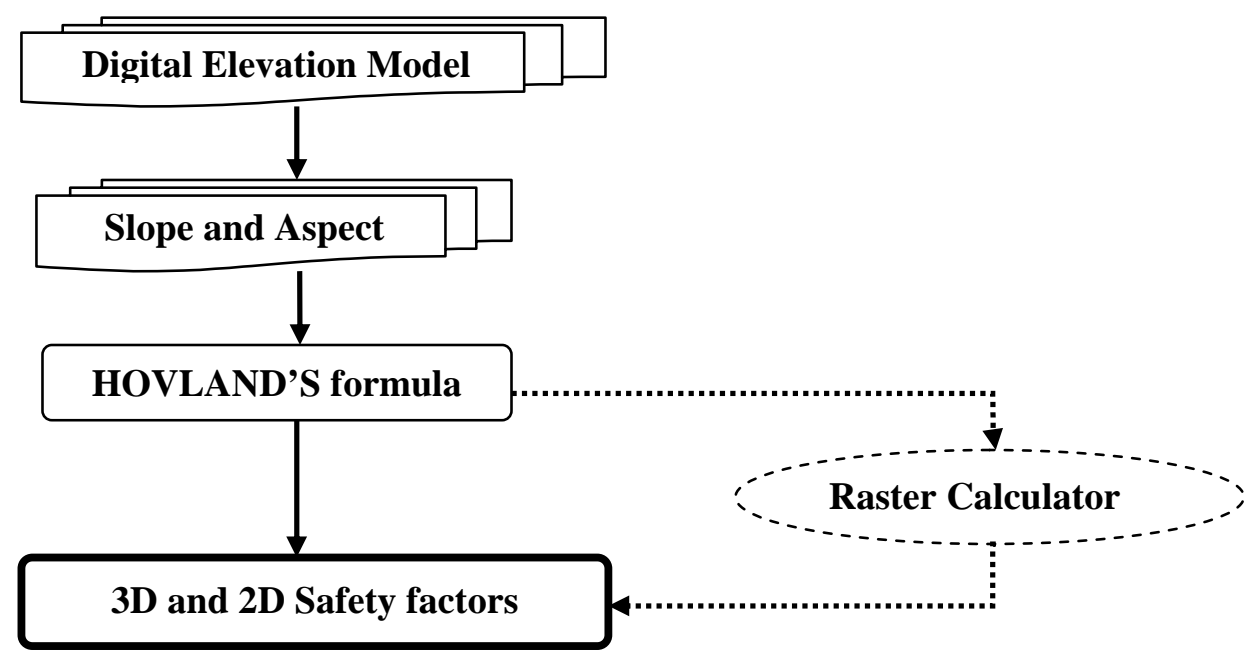

Fig. 4. Computing steps of safety factors

\section{III.RESULTS ANS DISCUSSION}

Results show that the safety factors in 2D and 3D vary linearly with the increase of the effective cohesion and the effective friction angle. 2D and 3D safety factors increase with the increase of effective cohesion and effective friction angle, which shows the effect of these two parameters on the slope stability analysis. We found also that $3 \mathrm{D}$ FS are always higher than 2D FS and the gap between the safety factors in $2 \mathrm{D}$ and $3 \mathrm{D}$ is approximately constant, and it is of the order of 0.17 (Fig. 5).
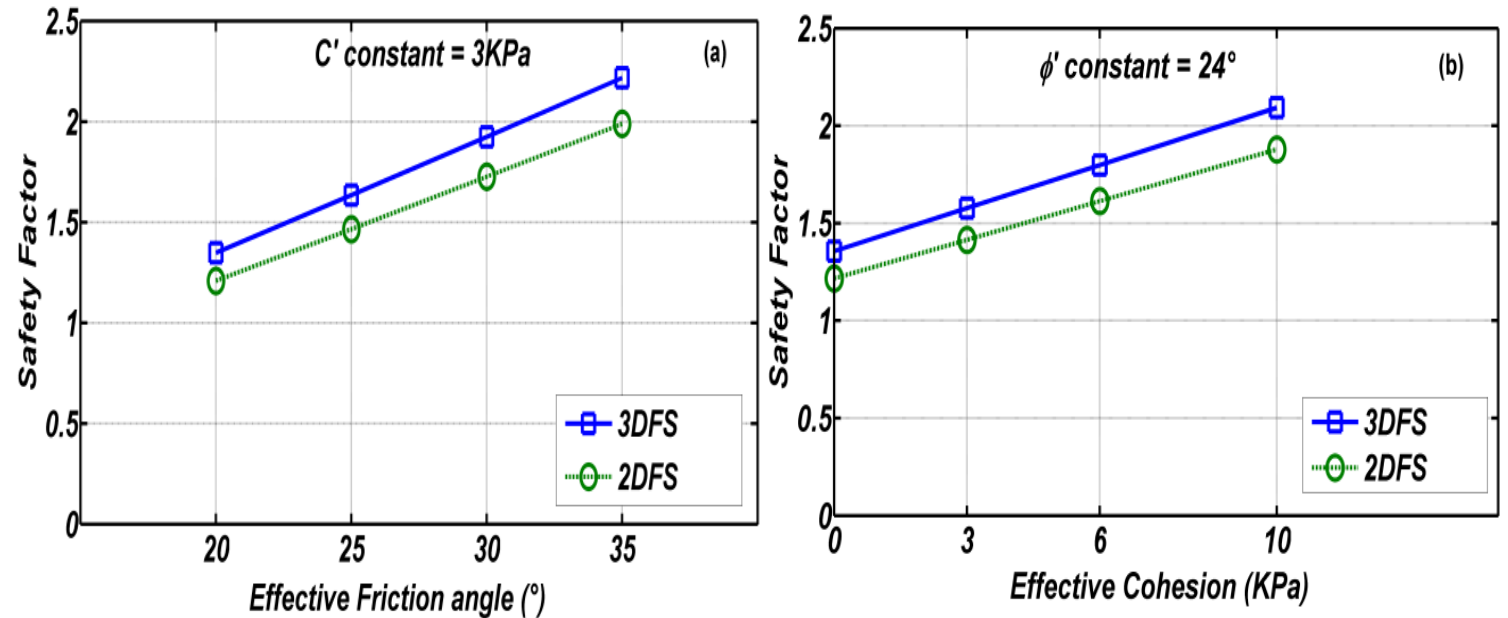

Fig. 5. Influence of the effective friction angle (a) and the effective cohesion (b) on the safety factor

The piezometric measurements revealed that the water table level varies from $0.5 \mathrm{~m}$ to $4 \mathrm{~m}$.

In the case of high water tables, $(\mathrm{Hw}=0.5 \mathrm{~m}$ and $\mathrm{HW}=1 \mathrm{~m})$, the safety factors in $2 \mathrm{D}$ and $3 \mathrm{D}$ are below 1 (Fig. 6), which indicates that the studied slope is unstable in the case of a rise of the water table at these depths. This being due probably to the effect of the pore water pressure $U$, which plays an important role in reducing the shear strength of the soil, which reduces the safety factor and therefore increases the risk of instability. 


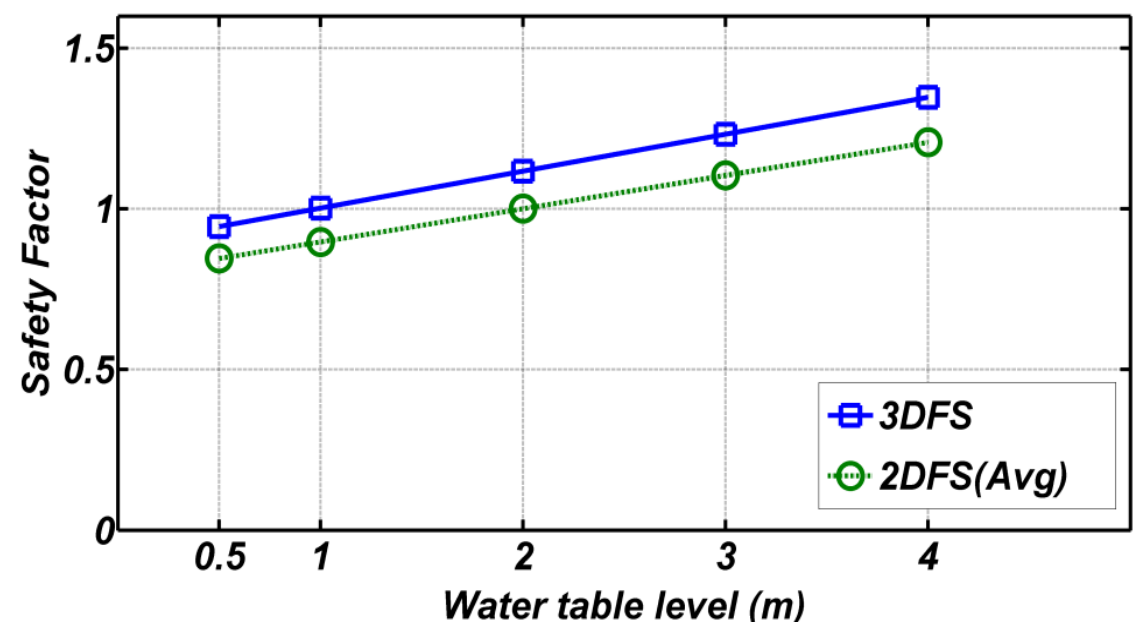

Fig. 6.influence of the water table level on the safety factor

For the water table depths $(\mathrm{Hw}=2 \mathrm{~m}, \mathrm{Hw}=3 \mathrm{~m})$ we note that the safety factor $(2 \mathrm{D}$ and $3 \mathrm{D})$ are greater than 1 , so the slope is in theory stable in the case of a considerable lowering of the water table at these depths. For lowest water table level $(\mathrm{Hw}=4)$, we found that the safety factor values in $2 \mathrm{D}$ and $3 \mathrm{D}$ are approximately the same that those found for the case of the slope without water table $\left(c^{\prime}=0\right.$, phi ' $\left.=24\right)($ Fig. 5(b)). This indicates that the influence of water table on the stability is insignificant at this depth. These results thus show, that the height of the water table and the water pressure distribution play an important role on the shear strength and on the safety factor in 2D and 3D.

TABLE I

Calculated safety factor results

\begin{tabular}{|c|c|c|c|c|c|c|}
\hline $\begin{array}{c}\text { Water } \\
\text { table } \\
\text { Hw (m) }\end{array}$ & 3D FS & $\begin{array}{c}\text { 2D FS } \\
\text { (Avg) }\end{array}$ & $\begin{array}{c}\text { 2D FS } \\
\text { (Left) }\end{array}$ & $\begin{array}{c}\text { 2D FS } \\
\text { (Mid) }\end{array}$ & $\begin{array}{c}\text { 2D FS } \\
\text { (Right) }\end{array}$ & $\begin{array}{c}\text { 2D FS(Avg) } \\
\text { / 3D FS }\end{array}$ \\
\hline $\mathbf{0 . 5}$ & 0.944 & 0.845 & 0.868 & 0.798 & 0.874 & 0.895 \\
\hline $\mathbf{1}$ & 1.002 & 0.897 & 0.920 & 0.847 & 0.928 & 0.895 \\
\hline $\mathbf{2}$ & 1.117 & 1 & 1.026 & 0.946 & 1.034 & 0.895 \\
\hline $\mathbf{3}$ & 1.232 & 1.104 & 1.132 & 1.043 & 1.141 & 0.896 \\
\hline $\mathbf{4}$ & 1.347 & 1.207 & 1.238 & 1.141 & 1.247 & 0.896 \\
\hline
\end{tabular}

2D safety factors have been calculated on three sections of the study area. Results of 2D stability analysis show that the safety factors differ in the three sections (Table1). Also the lower values of the Safety factors are those obtained from the middle section, this is probably due to geotechnical soil characteristics or variation in topography and water table level which indicates that this section is the most critical.

The ratio 2DFS(Avg) / 3DFS is less than 1 at all water table levels, this indicates that 3D safety factors obtained by Hovland's method are higher than those obtained in 2D. However, the variation of the water table level has no influence on the ratio 2DFS (Avg) / 3DFS. Gens has found that the percentage difference between $3 \mathrm{D}$ and 2D stability analysis ranges respectively from $3 \%$ to $30 \%$ with an average of $13.9 \%$ [15], as well as Duncan found that the 3D safety factors are almost 10\% higher than those obtained in 2D [16] which shows that these results are similar to those obtained from this study (FS3D $=1.11 \mathrm{FS} 2 \mathrm{D})$.

\section{IV.CONCLUSION}

In this paper we have presented a methodology of slope stability analysis using GIS. We have used several tools in ArcGis 9.3 to calculate the safety Factors in 3D and 2D using Hovland's method. Results indicate that the 3D safety Factors are higher than those in 2D for all water table levels. Also we found that the studied slope become instable for the highest water table levels $(0.5 \mathrm{~m}$ to $1 \mathrm{~m})$. This study revealed also that the Geographic information System can be used effectively for 3D and 2D slope stability analysis. 


\section{ACKNOWLEDGMENT}

My thanks are due to my supervisor Prof. Lahcen BAHI, Director of the Doctoral Study Center, and Professor of Geophysics at Mohammadia Engineering School, for his constant guidance and support.

\section{REFERENCES}

[1] Chang M.2002. A 3D slope stability analysis method assuming parallel lines of intersection and differential straining of block contacts. Canadian Geotechnical Journal. 39: 799-811.

[2] Ouadif L. Bahi L. Baba K. Akhssas A.2012. Study of Stability of a Highway Fill Application of the Analytical and the Finite Elements Methods. International Journal of Engineering Research and Applications (IJERA) . Vol. 2. Issue 1. Jan-Feb 2012.904-910.

[3] Baba K. Bahi L.Ouadif L. Akhssas A.2012 .Slope Stability Evaluations by Limit Equilibrium and Finite Element Methods Applied to a Railway in the Moroccan Rif . Open Journal of Civil Engineering. 2. 27-32.

[4] Hovland. H.J. 1977. Three-dimensional slope stability analysis method. ASCE Journal of the Geotechnical Engineering Division. 103(GT9): 971-986.

[5] Ugai. K. (1988). “Three-dimensional slope stability analysis by slice methods."Proc.. 6th Int. Conf. on Numerical Methods in Geomechanics.A.A. Balkema. Rotterdam. The Netherlands. 1369-1374.

[6] Hungr. O. (1987). "An extension of Bishop's simplified method of slope stability analysis to three dimensions." Geotechnique J.. 37(1).113-117.

[7] Huang C. Tsai C. Chen Y.2002. Generalized method for three-dimensional slope stability analysis. Journalof Geotechnical and Geoenvironmental Engineering; 128(10): 836-848.

[8] Fredlund. D. G.. and Krahn. J. (1977). "Comparison of slope stability methods of analysis.” Can. Geotech. J.. 14(3). 429-439.

[9] Lam. L. and Fredlund. D.G. 1993. A general limit equilibrium model for three-dimensional slope stability analysis. Canadian Geotechnical Journal. 30(6): 905-919.

[10] Carraea A. Cardinsli F. Guzzetti M. Reichenbach P.1995. GIS technology in mapping landslide hazard. geographical information systems in assessing natural hazards [M]. Kluwer. Dordrecht. Netherlands. pp 135-175 Anbalagan D. Landslide hazard evaluation and zonation mapping in mountainous terrain. Eng Geol 1992;32:269-77.

[11] Van Westen CJ.1998. GIS in landslide hazard zonation: a view. with cases from the Andes of Colombia. In: Martin FP. Heywood DI. editors. Mountain environment and geographic information systems. Taylor \& Francis. p. 35-165.

[12] Dai FC. Lee CF .2001. Terrain-based mapping of landslide susceptibility using a geographical information system: a case study. Canadian Geotechnical Journal; 38: 911-923

[13] Xie M. Esaki T. Zhou G. Mitani Y. 2003. Three-dimensional stability evaluation of landslides and a sliding process simulation using a new geographic information systems component. Environ Geol ;43(5):512-603.

[14] Chacon J. Irigaray C. Fernandez T. El Hamdouni R.2006. Engineering geology maps: landslide and geographical information systems. Bulletin of Engineering Geology and the Environment;65(4): 341-411.

[15] Gens A. Hutchison JN. Gavounidis S.1988. Three dimensional analysis of slices in cohesive soils.Geotechnique. $38:$ 1-23.

[16] Duncan.J.1996.State of art :limit equilibrium and finite -element analysis of slopes.ASCE journal of Geotechnical Engineering1996.122(7).577-596.

\section{AUTHOR PROFILE}

Mr.Ahmed BOUAJAJ PhD Student, Mohammadia Engineering School (E.M.I), Mohammed - V University Rabat, Morocco.

Prof.Lahcen BAHI Director of the Doctoral Study Center, and Professor of Geophysics, Mohammadia Engineering School (E.M.I), Mohammed - V University, Rabat, Morocco.

Prof.Latifa OUADIF PhD Professor of Geotechnical Engineering, Mohammadia Engineering School (E.M.I), Mohammed - V University, Rabat, Morocco.

Prof.Khadija BABA PhD Professor of Civil Engineering, Mohammadia Engineering School (E.M.I), Mohammed - V University, Rabat, Morocco. 